\title{
The impact of Media in the Socialization process in Albania
}

\begin{abstract}
Bukurie Lila
$\mathrm{PhD}$ candidate

bukurielila@yahoo.com

Abstract

Media is one of the main agents of socialization that affects youth the most. Young adults are majority time are surrounded by the media, which brings me to my main question, "How is Mass Media Affecting Socialization in Children and Young Adults in Albania?" To understand this question one must know and understand what socialization is. The socialization process is a very dramatic impact on a child's life. Socialization is a "Continuing process whereby an individual acquires a personal identity and learns the norms, values, behavior, and social skills appropriate to his or her social position". Mass media has enormous effects on our attitudes and behavior which makes it an important contributor to the socialization process. in some ways mass media can serve as a positive function. It helps there to be more diversity, we can learn more about things that are going on in different countries. It can help you learn new things you did not know. Sadly Media can serve as a negative function in young people life. Young people want to be accepted by society and the media creates the ideal image that tells you what the characteristics are to be accepted and to be able to fit in with society. They show what you should look like, how you can look like this, and where to go to buy these things that will make you look right. This is why many young women deal with anorexia because they want to look like the ideal type that the media displays. Media also influences young people to misbehave. Media shows that being deviant makes you cool and look tough and that it's okay to do deviant things. Statistics show that when young people watch violence on television it increases their appetites to become involved in violence. It opens their minds to violence and makes them aware of crimes and people acting deviant. Many people think that the media does not play a role in the socialization process as much as family, peers and education. But in fact the media plays a strong role in the socialization process. The aim of this study is to see the positive and negative effects that the Albanian media plays in the socialization process in Albania.
\end{abstract}

Key words: Socialization, media, violence, young people, social problems

\section{Introduction}

Nowadays, we don't suffer from a lack of information, by the contrary;today man is "bombarded" from all sides with animmensity of data. Selecting the right information requires a lot of ability to understand and analyze the information.Today no one can think his life without TV, radio, newspapers and the Internet. Making and sharing information is present in everyday communication of our society and inside the family. The media are organs that transmit information to a wider public through technical means. The mass media include: press, radio, television and the Internet. Freedom of mass media is provided in the Albanian constitution.

Internet is the main factor of spreading the information. By changing the means of communication, the process of education has also changed. Specifically in education affect, many individual factors that are family, school, social class, peer groups, media and the Internet, religion, political and other various events. This process continues throughout life (Frederik and Lavenir 2004).

Powerful influence on socialization of an individual has the media, through which the mass communications are made. "There is no doubt that the media influences people's attitudes and outlooks. Until the child becomes 18 years old, the most of his time he spends watching television and internet, than any other activities, except sleeping. Increasing of the impact of television is perhaps the only significant development of this century". It can be said that the Internet has also become a medium used excessively. However, often the reality that creates media is different from what it is actually. Erich From has claimed that "Media is a method of washout brains that has a hypnotist affect".

The media bombard our brains with information, editorials, analysis, commentary and significant political developments. No one is immune from the influences that they exert. Therefore, caring for them becomes inevitable process that lies at all levels, categories and social classes. Systematic research about the role of media in education of children and adolescents has been the basis of many studies. The same view is also common in the working of David Easton and Dennis Jeck (Easton and Jeck 2008). According to them, socialization is a process through which are reached cultural orientations and behavior patterns. Socialization is a gradual process of learning the norms, attitudes and behaviors that are accepted 
by the social system of today. The purpose of the media should be training and development of the individual to become good members of society and the socialization continues throughout life.

A key point of education from an early age to adult, is the creation of beliefs and values, which are long-lasting, so that the principles and advantages gained are stored for longer time.Media (theater, cinema, newspapers, magazines, radio, television, Internet), profoundly affect the outlook and attitudes of people (Maigret 2010).

The story about media impact in socialization

The theory of impact of Media in Education and Socialization has its beginnings in the U.S. in the 1970s as a response and protection from 'bad' media. Most of the materials that were produced at that time aimed to educate the parents from media. Since that time interest in education from media growed and materials already intend teachers and students in schools, encouraging and nurturing critical thinking among childrens. Models are already clearly outlined and there are a variety of them. (Tinder 1993)

Different countries conceive and organize the various forms of media impact in education and socialization focusing on the political, social and economic, with particular emphasis on the importance of using efficient and rational media. in Albania during the period of dictatorship, during the years 1945-1990, the only media in Albania was public television, which exert a great impact on people, because it was the only way information. Media education is characterized by a continuing debate over its fundamental goals and methods, just like any other field of education. So far very few teachers, or not at all, are trained to aware the people about the influence that has the media in the process of education (Frederik and Lavenir 2004).

The purpose of media education is to prepare children to understand and to participate actively in the media culture that surrounds them. The emphasis is on critical understanding and analysis, which are based on critical thinking skills and creative of the students. (Maigret 2010)

Basically, defensive approach seeks to protect children from the dangers of the media. To be sure, these risks are set out in different ways at different times and in different contexts. in some countries, initially the underlying concern was that cultural media educators. They have seen the media as a form of low culture, that would harm the child assessment values and virtues of high culture. in other words, the underlying concern is it moral. (Greenberg 2009)

Media educates the children with values and behaviors that are deemed to be inappropriate or harmful (for example, relating to sex and violence). Finally, and especially in the form of media education that took place in the 1970s - can be seen a political concern: the belief that the media are responsible for promoting false beliefs, political or ideological. in any case, media education is seen as a tool to entertain the children (Anderson 2001).

While these protective view of media education have been away from the replacement, there has been a gradual evolution in many countries for a less defensive approach. in general, countries with more mature forms of practice in media education, those which have a long history and stable model of evolution, have gone well beyond the defense. Media Education here is seen not as a form of protection, but as a form of preparation. It aims to protect young people from the influence of the media, and thus lead them to better things. Students are asked to make their own decisions. Moreover, media education aims to develop understanding of youth and their participation in media culture that surrounds them.

In this process, education media inevitably raises cultural, moral and political concersn, but it does it in a way that encourages active engagement, critical thinking of the students, instead of attending an orientation to a default position. (Giddens 1967)

\section{Television impact in socialization}

Television is a tool where a child fits in the best way during a certain time, and the television little by little takes time from other activities, that could be quite necessary for a child. Television unequivocally has positive and negative influences on young children. Television is a media that has more impact on people's lives.

In many developed societies, the time that children spend in front of screens is greater than the time thay spend in school. The impact of television on children depends on many factors, such as the number of hours spent in front of the small screen, their age, their personality, the fact of watching TV alone or with adult and finally the discussion they do or not with their parents about the content of what they have seen. in today's families, parents want to meet every desire of their children, and so they leave them for a long time in front of television. Children are being, that if they want to watch something they want to possess it. But, as Sami Frashëri, an Albanian Renaissance, and writer: "Children should be given what it needs, not what it wants". 
The positive side of watching television is that television can be entertaining, educational and can open new windows of information for children, enabling them to travel even where it may not be present, to teach reading and writing, other languages, different cultures and peoples, to attend various educational programs. The most important thing is to select programs that respond to the child's age. Television programs should be in conformity with the child's age. Emissions that are seen by children on television should be suggested by parents, and must be controlled by them. Otherwise, any negligence or deviation from this process can be very harmful for the children. in this way children can learn useful things, as well as useless, which affect their formation.

A child who is taught to stay in front of the television screen turns into an inactive child, he doesn't move and he doesn't go out to have a social life. The greatest responsibility for anything that happens to the child falls on the parents, for the sole reason that the child requires a special focus and support all the time not to create dependency on television.

Television viewed by children, without selection of programs and channels from parents, creates the opportunity for children to see violent scenes, which increases the chance for aggressive behavior in children, because the child thinks that a thing that can be watched on television can happen in reality and could be very true. This obviously affects the children. When they see violence on television constantly, begin to think that it is normal and acceptable by society, while society tries to stop this fenomen. Children internalize what they see, not knowing to distinguish between what should adopt and what not.

Concerning Albania, I think that children are facing with programs that has no values. Children are all the time under the influence of violent movies, crime, fraud, theft, moral degradation. in this context it should be recognized the impact of media on children, as well as a request for the materials selection process that children have the opportunity to follow through television. in conclusion, I think that children are being "bombarded" with ideas, thoughts, writing movies that instead of raising children with positive social feelings, humanity, solidarity, sexual restraint, respect the woman, do the opposite.

In a not very developed society like ours, the role of Television takes a huge social role. in our society the people trust very much to the television. in this case television has in its hand an historic role. Television in Albania, although not in its full formation has played a major role in changing old social mentalities, and has helped to move forward the Albanian society according to contemporary life. The moment that we live, gives us the right to analyze with more responsibility, the huge role impact of television.

We all are aware that television does not make people smarter, but even more ignorant. But it can orient their behavior, positively or negatively. Albanian society is fundamentally politicized and television has played its negative role. All televisions, according to supporters of the policy arm, have "wrecked" the viewer with political debates. Despite the personal nature that take emissions, depending on the production, the time has come to understand the role of television as a kay role in education and socialisation.

More than $50 \%$ of people wont to imitate the model viwed at the television. So it happens everywhere in the world. Albania doesn't make an exception. The problem that is facing Albanian society today concerning family violence, sexual violence, murders and suicide, are also causes driven by television. N. Postman writes: "No tool can be dangerous if users know the risks." But if you do not know society goes toward destruction.

The role of the internet in education

Internet in Albania is spreading too fast over the last 20 years. According to the latest data from the operators and the evaluation of the Electronic Communications and Postal (AKEP), the number of households that have Internet access until the middle of 2012 was approximately 140 thousand or approximately $17 \%$ of the total number of families, or $4.3 \%$ of the population. Usage value is about $30 \%$, so 30 peoples in 1000 use internet in Albania.

This figure is a relatively satisfactory as compare to 2008 was about $15 \%$. So is a qualitative increase between this period. in the focus of internet companies is youth. Since in the begining the early goal of internet companies was the new age people. in all Albanian cities gradually began to rise many internet rooms, almost turning into a fad.

According to the data, in Albania every year come into use 50 thousand new computers, but this number is even larger when we count used computers. If we create a map of internet usage in Albania, we will mark Tirana olored as red and the other places with an pale color. Tirana, is the epicenter of providers and internet users. Internet akses service is available for any city in Albania, but the weakness and hight cost of the service discourages the proliferation of its use in districts.

\section{Methodology of the study}

This part summarizes the main results and trends to a survey conducted by 100 persons aged $15-45$ years in Tirana about the internet usage and the reasons why people use it. The paper focuses on the use of the Internet according the users 
age, what are the main trends, why more Internet use, suggestions for improvement etc. Are interviwed about 100 persons of which 43 females and 47 males.

\section{The spread of the Internet in school}

Internet also spreaded in Albanian schools. According to an Albanian government project each school, about 2000 such throughout the country, have their own computer labs, with at least 5-15 computers connected to the network, but not all have effective internet connection at any time. Students say that they mostly use the internet for information related to the lessons, but also to connect with friends on social networks like facebook, twitter etc. Recent years the Albanian government has made substantial investments in order to spread the internet, putting it at the service of the administration, and the public.

Since 1999, all Albanian ministries have their own websites on the internet, and started gradually an implemented program called e-government, e-government or otherwise electronic government. The future of the Internet in Albania is like all other parts of the world. Albania has an exponential growth of the Internet, many Albanians are given to the new technological developments, have huge demand, although prices are still high compared to the region.

The main Trends of the Survey

We had 100 people survey asked randomly in Tirana found that $90 \%$ of respondents used the Internet and only $10 \%$ do not use it at all. Most users aged 15-20 years. The importance of online media, blogs and social media is increasing day by day, because of the ease that they offer and the opportunity to communicate with a wide audience (DeFleur n.d.). However, in Albania the development of this category of media has been delayed, mainly because of infrastructure, but also due to lack of interest.

Recently, has an increasingly attention and usage for this kind of media. in addition to traditional media websites online, there were new entrants in the media scene. These actors are usually in the form of news agencies or news gatherers. Their websites offer a range of information and topics, similarly with daily newspapers and outdoor media in general, which rarely have any specific target. Variety Information includes almost everything, from politics and current affairs, to gossip columns.

\section{Internet usage from our survey}

Our survey confirmed expectations regarding attendance by youths internet: the internet is the most used and preferred by children and young people of this age. More than half of the respondents and the youth said they used the Internet several times a day, while the other half said they use once a week. This high frequency of Internet use testifies to the close relationship that has the youth up to 32 years old with this kind of media and huge influence may be exercised in this regard.

In fact, as was seen from the survey, the most common reason to use the internet was frequenting social networks, where only a small fraction of respondents stated that they were using these networks. A wide use, although lower than social networks, have fun online and even somewhat less information. So, one can say with certainty that this age group uses this tool in an extremely wide, definitely more than traditional media. Maybe in some cases it can be said that virtual reality provided via the Internet occupies more place in the life of this age group than everyday reality.

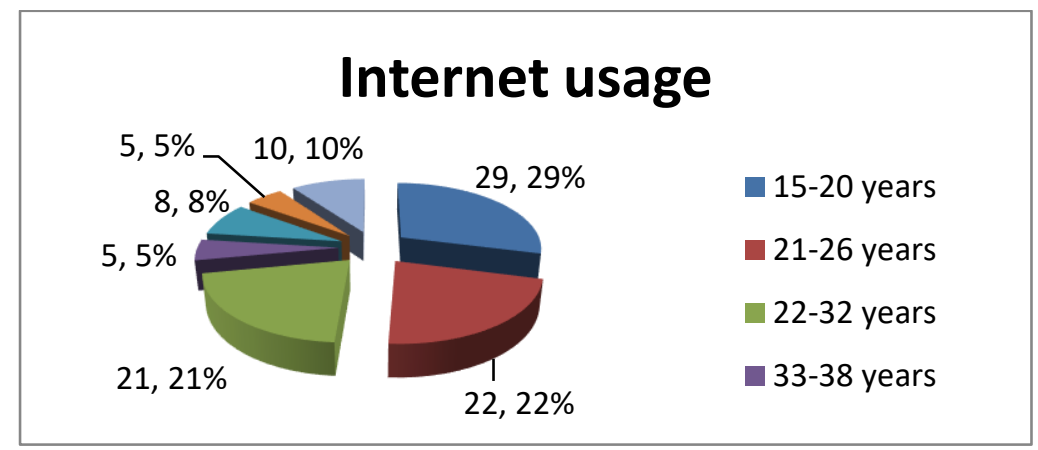

Graph 1, Internet usage in Albania 


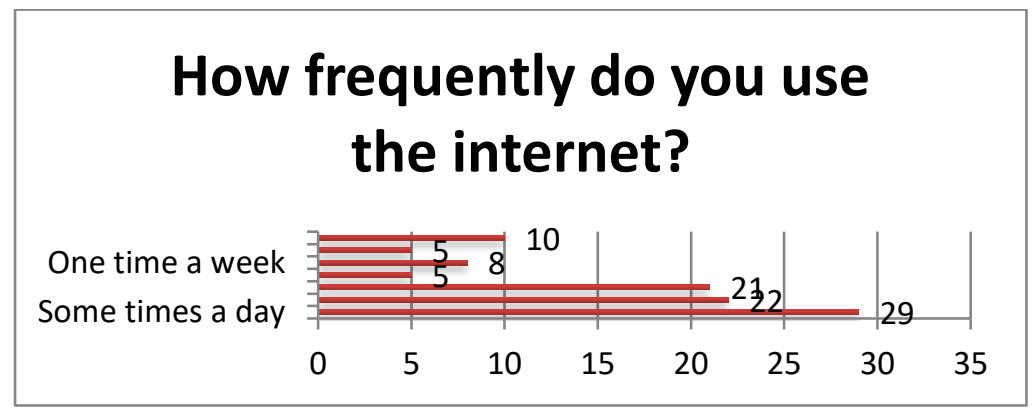

Graph 2, How frequently do you use the internet?

As it seems, 29 people out of 100 use internet at least once a day, but in fact most of them used internet several times a day. Meanwhile, only 10 people said they use the Internet. The wide use of internet is so obviously connected with the growing importance that he has received, but also to attract that age group of young people especially.

Also, the extent of its spread in the country, especially in the capital, is another factor. So, when asked where mainly they use the Internet, the vast majority of respondents said they use it in mobile and in the home and that testifies the ease of access this age group has to this media.
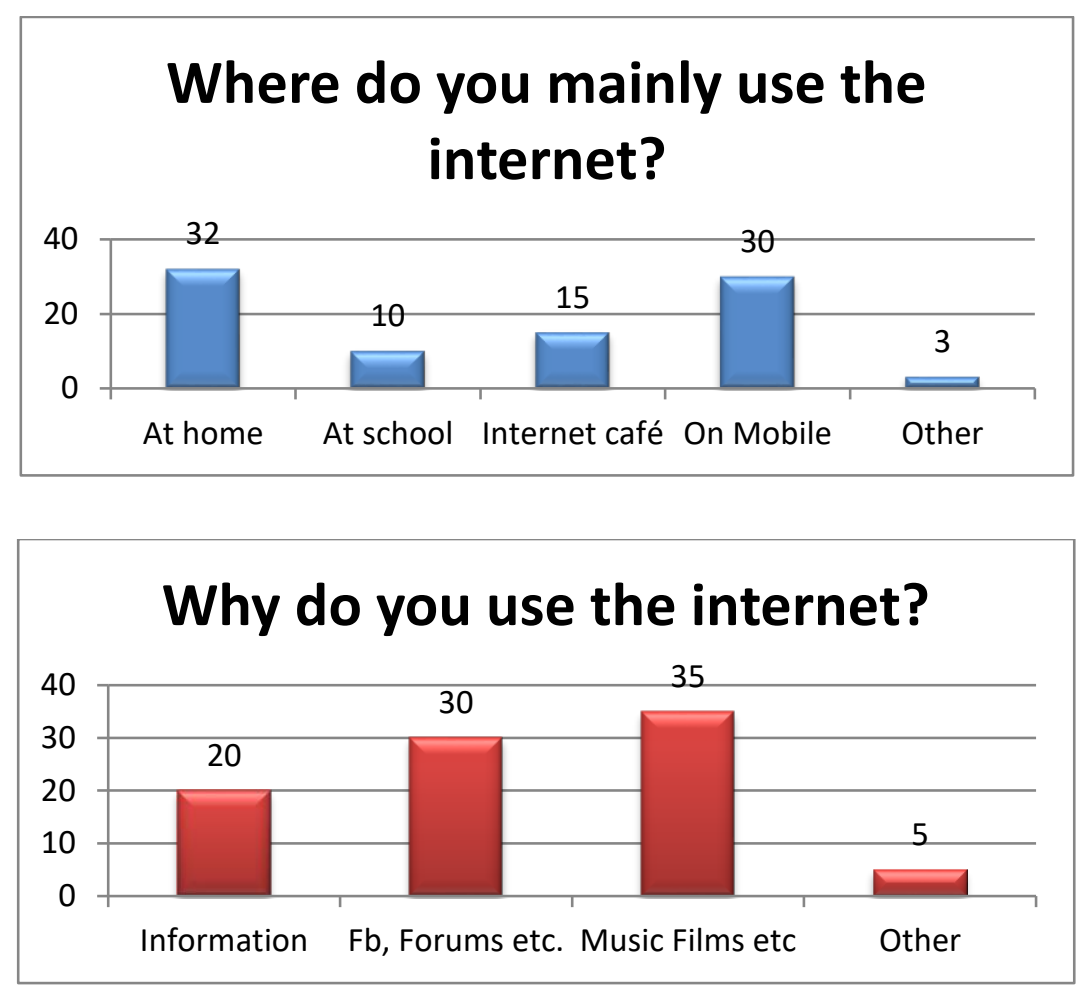

Graph 3, Why do you use the internet?

As expected, the majority of respondents used the Internet for social media, which was significantly more popular than the other categories. However, there were few of those who use entertainment or information. Very few of the respondents said they use for other purposes, of which the most cited were reading books and taking various materials for school projects. 
Given the wide use of Internet by this group to engage in social media, they were asked about the frequency and visibility of their profile, as well as how often they update this page. While the vast majority of seeing at least once a day to update the profile figures were lower, but still significant.

\section{How many times do you click the social networks?}

39-44 yeas/once a month 27-32 years/once a week 15-20 years/every day

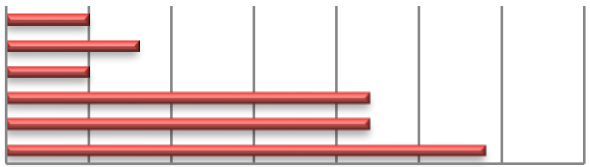

0 $5 \quad 10 \quad 15$ $20 \quad 25 \quad 30$ 35

Graph 4, How many times do you click the social networks?

Given the high exposure of children and young people to the Internet, especially social media, and little opportunity to control the adults in this regard, respondents were asked if they had interference from adults to use the internet and if they had problems with privacy in social media. 30 of 100 respondents said they had interference from parents to use the internet, but interventions were mainly related to the time spent and not with the purpose of using the Internet. On the other hand, only 23 respondents said they had had problems with privacy on social networks, while others said no.

The importance that respondents have given different media

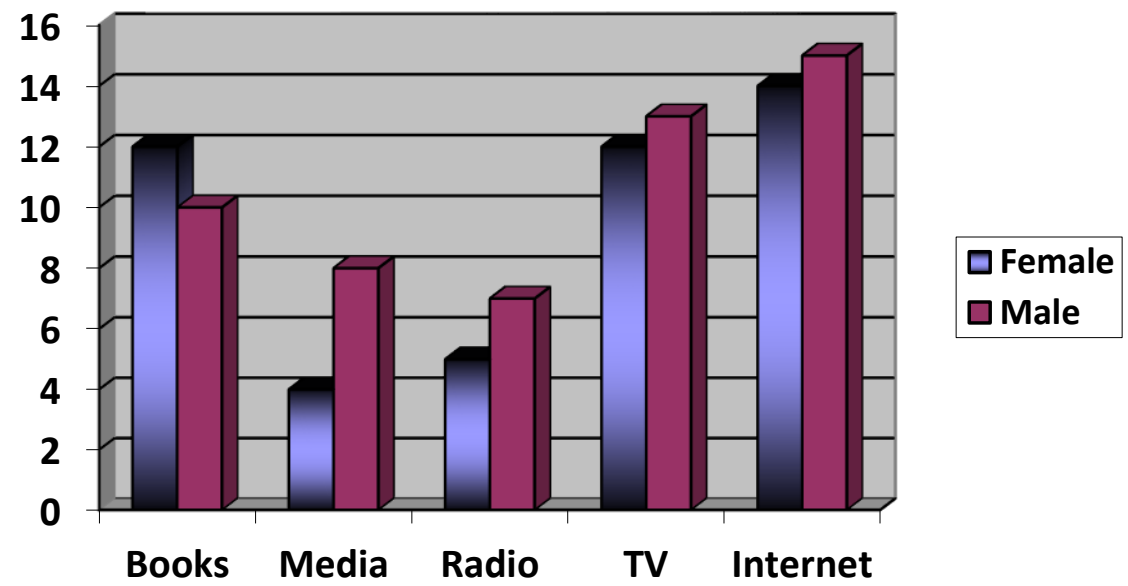

As it can be seen from the cumulative graph for all media, has a marked preference for the Internet in terms of importance, which was expected. Somewhat surprising is the prominence given to books, occupying nearly half of preferences for a grade of "1." Although it is clear preference for the Internet, again, has an apparent competition between him and books. Meanwhile, traditional media are significantly less preferred, especially the press and radio. Television seems to have taken the average preferences.

\section{How safe are our children in front of computers?}

In recent years we have seen a large increase in the use of internet, online communication and dissemination of information in our country. The speed with which the increased use of the internet is amazing. We have this growth of its use at work, school and in everyday life obviously. Use of the Internet has brought a number of benefits to society by reducing 
geographical distances and facilitating the dissemination of information to the maximum. Many psychologists believe that the Internet has brought a distinct sense of community life. The Internet has brought a number of benefits for children and young people, facilitating their social contacts, improving writing and language. But, beyond the great benefits that come from the Internet, the rapid development of technology, the growth of online services and other applications, unfortunately, have to admit that this increase in use is not accompanied by the necessary measures to be protected from the dangers that brings this technology especially for children.

In many cases, technological developments in the field of Internet are used to self harm Internet users. It is a fact today that the development and distribution of internet moves much faster than the safeguards against abuse of it. I would like to enumerate the consequences and dangers of internet use for children brings and in particular: First, there is a much greater risk of sexual harassment on the Internet. This is a very serious problem indeed. Thus, according to a survey conducted in the U.S., about $19 \%$ of children aged 10 to 17 years, who were regular Internet users were sexually harassed at least once a year. One in seven children stated that the harasser was also tried contacting them by phone or by mail. Risk that children fall into the hands of these online teaser is high for two reasons: the Internet is easily aksesushëm children.

On the Internet, the harasser is very hard to identify. The Internet gives the opportunity harasser remain anonymous or be presented with another identity. One problem with sexual harassment on the Internet is their failure. Studies have clearly that most children do not report the harassment or to parents or the police. Is a risk that children face pornographic picture. Although it is very difficult to give an exact number of children who are faced with these images, what we can say is that there are currently about 14 million ëebsit-of pornographic content, with 1 million of them contain images of children.

The large number of websit-tion is due because the Internet is seen as a unique, safe, easy to access by anyone for selling, collecting child pornography. Such views have a very bad impact on the formation of children, except for those selling these materials also aim to "normalize" the activity of these children. Often children who participate in these movies are smiling or making facial expression indicating consent. Which in most cases is not true. Is a risk that children face violence scenery.

The possibility remains high that children come into contact with domestic scenery including images, call for acts of violence, acts of racial, video or images of suicide or instructions on how to commit suicide. But according to a study that was conducted in the U.S., about $39 \%$ of children report having visited a web where content has been "musical violence", this is a kind of music "SOP" that foster hatred against other singers. While 20\% indicate that they have seen scenes of violence.

\section{Prevention of these negative consequences}

Above, I tried to explain the main negative effects of the Internet on children. But, anyway, these negative effects can be avoided. in recent years there has been a growing interest in many countries to discuss and find ways on how to protect children from abuse that may come through the Internet. An initiative is been taken by UNESCO, which was predicted later in the Convention of the Rights of the Child. Convention in its Article 17 imposes an obligation on states to take all measures to protect children from information and electronic materials that can harm their wellbeing. Anyway to prevent the risks of developing the above seems a lot of responsibilities and close cooperation between government bodies and parents on the other. in this regard, much remains to be done in our country and chances are that more be done in this direction. for simplicity it will be divided into two types of measures that can be taken: governmental actions and measures that parents can take themselves.

\section{Measures that can be taken by government}

Government is responsible for the welfare of its citizens in particular the children. This is clearly stated in our Constitution. The government has all financial possibilities, human resources, and also the decision to take such measures. Relying to the practice of other countries, I think that it is essential to adopt a special law to protect children on the Internet.

A good model may be the law of the United States. This is a law that was approved in USA in 2000. Law requires the placement of a filter for the internet access of children, especially in schools or in bookstores. The law makes detailed adjustments, for example how this filtering will be done and what should not of allowed. The government should also establish a special institution (Watch-dog) to identify and monitor website visited mostly by Albanian children.

\section{Measures that can take parents}

A large part of the responsibility lies with the parents. They can do a lot of things in order to their children do not fall prey to the above risks. Parents can take the following measures: Do not place the computer in a child's room, but in a more open space, the salon will be better. Salon is an open place, where stay other family members and so children will be afraid to visit certain website. The problem here is that children do not use the internet only in their home but in the school also. Thus, according to a study in the U.S., about $45 \%$ of teenagers enter the Internet in many places like, in school, in the 
library, at home or at friends' Internet centers. Occasionally you look at the computer screen to see what site is visiting the child.

Your child needs his freedom, and by this act of yours might feel threatened. Try to be attentive when you see at the screen, this action should not be perceived as a control, but as a curiosity by your part. Ask what your child is visiting, ask if you do not know how to do something on the computer etc.. Talk about the dangers of navigation on the Internet. Build an open communication with your child and ask if anyone tries make a friendship with him.

\section{Role of the press and media in the individual socialization}

The media play a dominant role in the lives of young people. Comprehensive media presence and mediatization of society primarily affect the formation of their identity. Being aware of the role of the media, young people need to have some skill or what is called media competence. Here enters knowledge and ways of using technical means and media language and the ability to make distinctions between different media.

In democratic countries newspapers carry important public functions. It not only transmits new information constantly, but also criticizes and controls addressing issues of public importance, as well as present events in the most accessible and fun for readers. Through commentary and analysis published in newspaper helps to build a critical judgment of the citizen for a functional democracy.

Social function of the media is important for living together in modern societies, in addition to traditional factors such as the family, schools, religious institutions, etc.. Media offers orientation in the thinking patterns and behavior, images and typology for children and youth.

\section{Conculsions}

Television, press, Internet and other media are estimated to have a major effect on the development of human identity and their process of socialization.

Although Albania has a total lack of research for the emissions and programs that are mostwatched, it feels the spirit of the great political impact they are having on people at different times. Experts believe that television and the internet are very powerful agents of socialization of the individual.

Modern society where we live is rapidly changing.Principal key is to work constantly with people. The phenomenon of socialization shows that the individ is socialized throughout the life. The more society develops, the more free and democratic it is, the better people will socialize. If anyone wants to reform society, he must convince people for the superiority of its ideas, he may create belief and trust in them. Such a role along with many other agents is played by media. If they will be free and democratic, the objective will be to reflect social reality. in this context better orientate future generations to be better positioned to the next life.

\section{References}

[1] Anderson, Daniel. Early Childhood Television Viewing and Adolescent Behaviour. . Boston: Blackwell , 2001.

[2] DeFleur, Melvin. DeFleur, Melvin L. \& Sandra Ball-Rokeach (1989): Theories of Mass Communication (5th edn.). . NY: Longman : White Plains.

[3] Easton, David, and Dennis Jeck. Children in the political system. McGraw-Hill Book Company, 1969, 2008.

[4] Frederik, B., and Catherina Bertho Lavenir. Historia e medias. Tiranë: Instituti Shqiptar i Medias, 2004.

[5] Giddens, Anthony. Sociology. Çabej, 1967.

[6] Greenberg, E. Political Socialization. 2009.

[7] Maigret, Eric. Sociologjia e komunikimeve dhe mediave. Tirane: UET Papirus, 2010.

[8] Tinder, Glen. Mendimi politik. Boston, USA: Masacustes University, 1993. 